\title{
Systematic review of diarrhea duration and severity in children and adults in low- and middle-income countries
}

\author{
Laura M Lamberti", Christa L Fischer Walker and Robert E Black
}

\begin{abstract}
Background: Diarrhea is a leading cause of morbidity and mortality globally; yet the overall burden of diarrhea in terms of duration and severity has not been quantified. As improvements in treatment lead to decreases in diarrhea mortality, it is important to understand the substantial impact of diarrhea morbidity on disability among children and adults worldwide.
\end{abstract}

Methods: We conducted a systematic review to generate estimates of duration and severity outcomes for individuals 0-59 mos, 5-15 yrs, and $\geq 16 \mathrm{yrs}$, and for 3 severity indexes: mild, moderate, and severe.

Results: We estimate that among children under-five, $64.8 \%$ of diarrheal episodes are mild, $34.7 \%$ are moderate, and $0.5 \%$ are severe. On average, mild episodes last 4.3 days, and severe episodes last 8.4 days and cause dehydration in $84.6 \%$ of cases. We estimate that among older children and adults, $95 \%$ of episodes are mild; $4.95 \%$ are moderate; and $0.05 \%$ are severe. Among individuals $\geq 16 \mathrm{yrs}$, severe episodes typically last 2.6 days and cause dehydration in $92.8 \%$ of cases.

Conclusions: Moderate and severe episodes constitute a substantial portion of the total envelope of diarrhea among children under-five (35.2\%; about 588 million episodes). Among older children and adults, moderate and severe episodes account for a much smaller proportion of the total envelope of diarrhea (5\%), but the absolute number of such episodes is noteworthy (about 21.5 million episodes among individuals $\geq 16 \mathrm{yrs}$ ). Hence, the global burden of diarrhea consists of significant morbidity, extending beyond episodes progressing to death.

\section{Background}

Diarrhea is a leading cause of morbidity and mortality across all age groups and regions of the world. Among children 0-59 months of age, diarrhea is responsible for 1.236 million deaths annually and is the second leading cause of death in this age group [1]. Though mortality rates among older children, adolescents, and adults are lower than those observed in children under five, diarrhea still poses a substantial burden accounting for approximately 2.8 billion diarrhea episodes among older children, adolescents, and adults [2].

Given the importance of diarrhea as one of the foremost causes of global morbidity and mortality, it is essential to quantify factors, such as duration and

\footnotetext{
* Correspondence: llambert@jhsph.edu

Department of International Health, Johns Hopkins Bloomberg School of Public Health, 615 N. Wolfe St, Baltimore MD 21205, USA
}

severity, critical to quantifying the overall burden of disease attributable to diarrhea. Comprehensive estimates of diarrheal duration and severity will allow for the more accurate assignment of disability adjusted life years (DALYs) in terms of years lost to disability due to diarrheal illness. While various studies conducted throughout the world report on the duration and severity of diarrhea, comprehensive estimates do not exist in the literature. Furthermore, there is a lack of consistency in methods for defining severe, moderate, and mild diarrheal episodes despite the existence of severity scales, such as the Hjelt, Vesikari, and Clark scoring systems, which assign an overall degree of severity based on the sum presentation of symptoms [3-5]. We therefore conducted a systematic literature review with the goal of consolidating available data on the duration and severity of diarrhea and describing the overall burden of

\section{Ciomed Central}


episodes among children and adults in low- and middleincome countries.

\section{Methods}

\section{Search strategy and selection criteria}

We systematically reviewed all literature published from 1990 to 2010 to identify studies reporting measures of diarrhea duration and severity in children and adults. From May 20-27, 2010, we searched in Pubmed using combinations of $\mathrm{MeSH}$ search terms: diarrhea, gastroenteritis, duration, persistence, severity, infant, child, teenage, and adult.

We initially screened all unique publications for eligibility based on the relevancy of title and abstract; we then screened the full manuscripts for inclusion and exclusion criteria. We included randomized controlled trials (RCTs), cohort, and observational studies published in any language and conducted in any country. Included studies contained data on diarrhea duration and/or severity in children and/or adults. We excluded studies with unclear methodology and diarrhea recall beyond 2 weeks. We accepted studies defining diarrhea as the passage of $\geq 3$ watery stools in a 24-hour period; we also considered mother's report of a change in usual stool consistency or frequency for infants $\leq 11$ mo of age, and the diagnosis of diarrhea by a physician or nurse as valid case definitions. We excluded studies describing diarrhea deaths alone since duration and severity outcomes of episodes resulting in death are not generalizable to all diarrhea episodes. We also excluded reports of nosocomial outbreaks, diarrhea due to known chronic or non-infectious illness, and studies that limited inclusion to one etiologic agent. For analytical purposes, we did not include studies that combined outcomes across child/adult age categories or inpatient/ outpatient status. Furthermore, for duration outcomes, we included studies on the natural course of diarrhea episodes and excluded those reporting on acute or persistent episodes alone.

\section{Data abstraction}

We abstracted measures of diarrhea duration and severity for all ages; for presentation purposes we grouped these data into 3 distinct age categories: 0-59 mos, 5-15 yrs, and $\geq 16$ years of age. For studies stratifying outcomes by treatment or HIV-status, we only abstracted data on placebo and HIV-negative individuals, respectively.

We abstracted three outcomes describing diarrhea duration: mean or median duration-reported as the number of days per episode of diarrhea, and the proportion of total diarrheal episodes that became persistent $(\geq$ 14 or $\geq 15$ days). If the proportion of persistent cases was skewed due to an intentional sampling bias or matching, we did not include the study for this outcome. To ensure capture of the full length of diarrheal episodes, we also excluded studies solely reporting the duration of diarrheal episodes at baseline.

Multiple outcomes were reported as measures of severity. We abstracted the proportion of individuals suffering from diarrhea with mild, moderate, severe, or any dehydration; vomiting; and bloody stools. We classified necessitating ORS or intravenous fluids as any dehydration. For studies assessing dehydration by both physician perception and WHO classification for dehydration, we utilized the latter. Likewise, if possible, we abstracted outcomes assessed by physicians or trained health workers in place of those estimated by mothers or caregivers. Additional severity outcomes included the mean stool volume $(\mathrm{g} / \mathrm{kg} /$ day $)$ and mean stool frequency (stools/day). We also abstracted the proportion with low (< $40 \mathrm{~g} / \mathrm{kg} /$ day), medium (40-70 g/ $\mathrm{kg} /$ day), and high (> $70 \mathrm{~g} / \mathrm{kg} /$ day) stool volume. For stool frequency, we abstracted the proportion low (1-5 stools/day), medium (6-9 stools/day), and high ( $\geq 10$ stools/day), as well as the proportion with $>5$ stools/day and $>3$ stools/day.

We did not find any studies able to quantify the proportion of episodes that remain mild/moderate or that progress to severe. We therefore used care-seeking behavior among caregivers of children $<5$ years of age as a proxy for diarrhea severity in this age group. We abstracted care-seeking behavior from the Demographic Health Surveys (DHS) [6]. The DHS reports the number of children $\leq 35$ months of age with diarrhea in the two weeks preceding the survey for whom care was sought, as well as the number who were not taken to a health provider.

\section{Data analysis}

We used STATA 10.1 to generate combined estimates and $95 \%$ confidence intervals for all duration and severity outcomes [7]. To ensure that confidence intervals were lower bound by zero for all outcomes and upper bound by one for proportions, we fit a logistic regression model to data reported as proportions and a Poisson regression model to continuous outcomes. All outcomes were weighted by sample size, which consisted of the total number of episodes. For study designs assessing only one episode per individual, the number of children or adults with diarrhea was considered the total number of episodes. We used the reported diarrheal incidence (number of episodes per child-year) to estimate the sample size for studies evaluating multiple episodes per child without reporting the total number of episodes. We conducted separate analyses for each study type-community, hospital-based inpatient and hospital-based outpatient.

Using the DHS data, we calculated region-specific averages for diarrhea care-seeking. We also calculated the median global estimate of diarrhea care-seeking 
across regions. The global estimate was used to inform our model describing the total envelope of diarrhea among children under five. Mild cases were defined as those for which no care was sought, and moderate cases were defined as those for which care was sought through a health provider. We assumed that mild and moderate episodes were best described by the duration and severity outcomes derived from community-based studies and hospital outpatient studies, respectively. We used the proportion of outpatient cases presenting with severe dehydration to determine the percentage of moderate cases which progress to severe. Duration and severity outcomes derived from hospital inpatient studies were assumed to best describe severe cases. Table 1 summarizes the algorithms used to determine the proportion of mild, moderate and severe cases occurring among children 0-59 mos of age; Table 1 also lists the source of duration and severity outcomes assumed to best describe each diarrhea category.

We also designed a model to describe the total envelope of diarrhea among individuals $\geq 16$ years of age. We assumed that mild cases were comprised of cases occurring in the community without dehydration, and moderate cases were comprised of the proportion of community cases with any dehydration. In keeping with the assumptions made for the model describing the total envelope of diarrhea among children under-five, we used the proportion of outpatient cases presenting with severe dehydration to determine the percentage of moderate cases progressing to severe. We also assumed that community, hospital outpatient, and hospital inpatient studies best described the duration and severity profiles of mild, moderate, and severe cases, respectively (See Table 1).

\section{Results}

\section{Systematic literature review}

The systematic literature search yielded 5708 titles for children (Figure 1), of which we identified 41 and 27 studies for inclusion in the analysis of duration [8-48] and severity $[8,9,16,19,21,22,25,26,36,39,43,45,49-63]$, respectively. All included studies reported data on children 0-59 months of age. One duration study also reported outcomes on children 5-15 years of age [24]; no included studies reported data on severity outcomes among older children. Only one study was conducted in a high income country [48]. Of the 8049 titles identified for adults (Figure 1), we included four in the duration analysis [24,64-66], and six in the severity analysis [53,64-68]. All but two studies reported data from lowand middle-income countries (LMICs) [65,66]. Across analyses, we included 61 unique studies with study locations spanning across six WHO geographic regions (Figure 2).

\section{Duration of diarrheal episodes}

Among children 0-59 months of age, the weighted mean duration was 4.3 days among cases assessed in the community and 8.4 days among hospital inpatients in LMICs (Table 2). The mean and median duration reported by the included study conducted in a highincome country were 2.2 days and 1 day, respectively.

The sole study conducted among children 5-15 years of age reported a mean duration of 2.7 days for episodes assessed in the community (Table 2). The reported mean duration of episodes among adults $\geq 16$ years of age was 3 days in the community and 2.6 days among hospital outpatients in LMICs (Table 2); in high-income countries, the mean duration of diarrhea was 2.6 days in the community and 4.6 days among outpatients.

\section{Severity of diarrheal illness}

Any dehydration was the outcome most frequently cited as a measure of diarrhea severity among children under five. The weighted mean proportion of episodes categorized with any dehydration was $7.3 \%$ for episodes assessed in the community, $84.6 \%$ among hospital inpatients and 51.4\% among hospital outpatients (Table 3).

Table 1 Algorithms used to determine the total envelope of childhood and adult diarrhea

\begin{tabular}{|c|c|c|c|}
\hline $\begin{array}{l}\text { Envelope of } \\
\text { Diarrhea }\end{array}$ & Severity & Algorithm (Data Source) $^{1}$ & $\begin{array}{c}\text { Source of Duration \& Severity } \\
\text { Outcomes }\end{array}$ \\
\hline \multirow{3}{*}{$\begin{array}{l}\text { Childhood } \\
\text { Diarrhea }\end{array}$} & Mild & Proportion not seeking care (DHS) & Community-based studies \\
\hline & Moderate & $\begin{array}{c}\text { Proportion seeking care (DHS) } \\
\text { Proportion outpatients without severe dehydration (MA) }\end{array}$ & Hospital outpatient studies \\
\hline & Severe & $\begin{array}{c}\text { Proportion seeking care (DHS) } \\
\text { Proportion outpatients with severe dehydration (MA) }\end{array}$ & Hospital inpatient studies \\
\hline \multirow[t]{3}{*}{ Adult Diarrhea } & Mild & Proportion community-based cases without dehydration (MA) & Community-based studies \\
\hline & Moderate & Proportion community-based cases with any dehydration (MA) & Hospital outpatient studies \\
\hline & Severe & $\begin{array}{l}\text { Proportion community-based cases with any dehydration Proportion outpatients } \\
\text { with severe dehydration (MA) }\end{array}$ & Hospital inpatient studies \\
\hline
\end{tabular}

\footnotetext{
${ }^{1}$ Data Sources: DHS Global average based on DHS report of diarrhea careseeking among children $\leq 35$ mos; MA meta-analyses reported here
} 


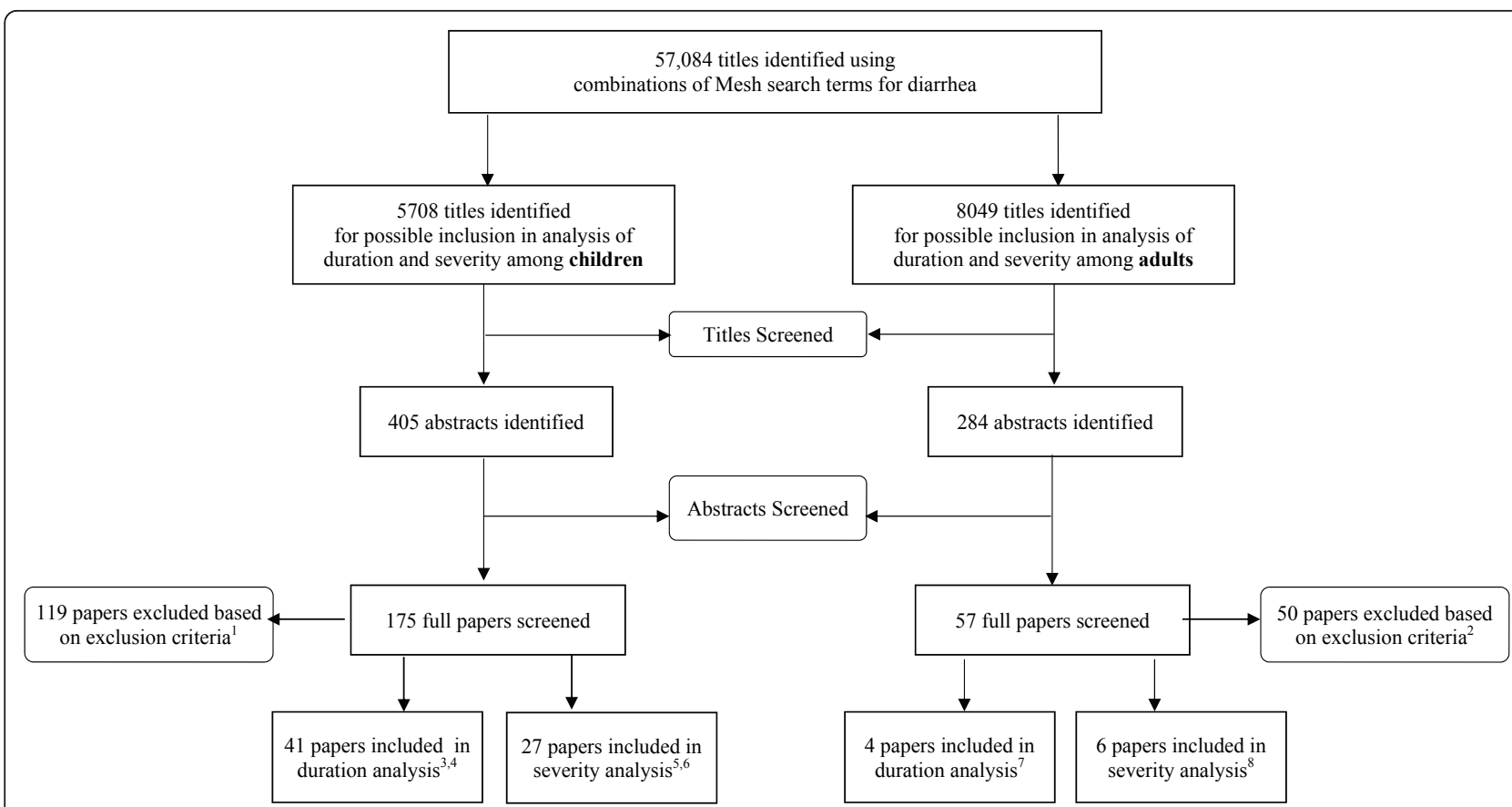

Figure 1 Flow chart diagram of the systematic review process. ${ }^{1}$ Main reasons for exclusion: report of one etiologic agent $(n=30)$ inadequate definition of diarrhea $(n=15)$; overlapping age categories $(n=17)$; no outcome of interest $(n=12)$; diarrhea recall beyond 2 weeks $(n=11)$; unclear/problematic methodology $(n=11)$; data in unusable form $(n=6)$; full episodes not followed $(n=6)$; not representative of general population $(n=4)$; combined data on hospital inpatients \& outpatients $(n=7) .{ }^{2}$ Main reasons for exclusion: report of one etiologic agent $(n=20)$; overlapping age categories ( $n=12)$; not representative of general population $(n=5)$; report of nosocomial infection $(n=3)$; unclear/problematic methodology $(n=3)$; diarrhea recall beyond 2 weeks $(n=4)$; inadequate definition of diarrhea $(n=1)$; no outcome of interest $(n=1)$; combined data on hospital inpatients \& outpatients $(n=1) .{ }^{3}$ All studies reported data on children 0-59 mos of age; one study reported data on children 5-15 yrs of age. ${ }^{4}$ Study design: cohort $(n=27)$; RCT $(n=10)$; case-control $(n=4)$. Study location: community-based ( $n$ = 34); hospital-based $(n=7)$. ${ }^{5}$ All studies reported data on children 0-59 mos of age, only. ${ }^{6}$ Study design: cohort $(n=15)$; RCT $(n=5)$; casecontrol $(n=7)$. Study location: community-based $(n=10)$; hospital-based $(n=17) .{ }^{7}$ Study design: cohort $(n=2) ; R C T(n=2)$. Study location: community-based $(n=2)$; hospital-based $(n=2)$. ${ }^{8}$ Study design: cohort $(n=4)$; RCT $(n=2)$. Study location: community-based ( $\left.n=2\right)$; hospitalbased $(n=4)$.

Any dehydration was also the most frequently reported measure of diarrhea severity among individuals $\geq 16$ years of age (Table 4). The weighted mean proportion of episodes presenting with any dehydration was $92.8 \%$ for hospital inpatient studies, $30.1 \%$ for hospital outpatient studies, and $5.0 \%$ for community studies.

\section{Diarrhea care-seeking practices}

The DHS-based regional average and global median proportions of care-seeking for diarrhea among children under three years are presented in Table 5. Care-seeking for diarrhea was highest in North Africa/West Asia/Europe (41.0\%) and lowest in South/Southeast Asia (31.0\%) and West/Middle Africa (26.9\%). The median global estimate of care-seeking for diarrhea among children under-five was $35.2 \%$

\section{Estimating the total envelope of diarrhea}

Figure 3 describes the total envelope of diarrhea morbidity among children 0-59 mos of age. Using care- seeking as a proxy for quantifying the proportion of diarrhea episodes which might be considered "mild", we estimate that $64.8 \%$ of episodes are mild and the remaining $35.2 \%$ of cases are moderate. Of these moderate cases, $1.4 \%$ will become severe (i.e. $0.5 \%$ of all cases). Using the data from community-based studies we estimate that mild cases last for 4.3 days. We estimate that $15.4 \%$ of moderate cases become persistent and $51.4 \%$ involve some dehydration. For severe cases, we applied the estimates derived from inpatient studies and thus assumed that severe cases endure 8.4 days with $84.6 \%$ resulting in dehydration. Since included outpatient studies did not report mean duration, we estimated the mean duration of moderate cases by averaging that of mild and severe cases; thus, moderate cases last approximately 6.4 days.

Figure 4 describes the total envelope of diarrhea burden among individuals $\geq 16$ years of age. Since severe dehydration was not reported by any of the outpatient studies included in this review, we determined the 


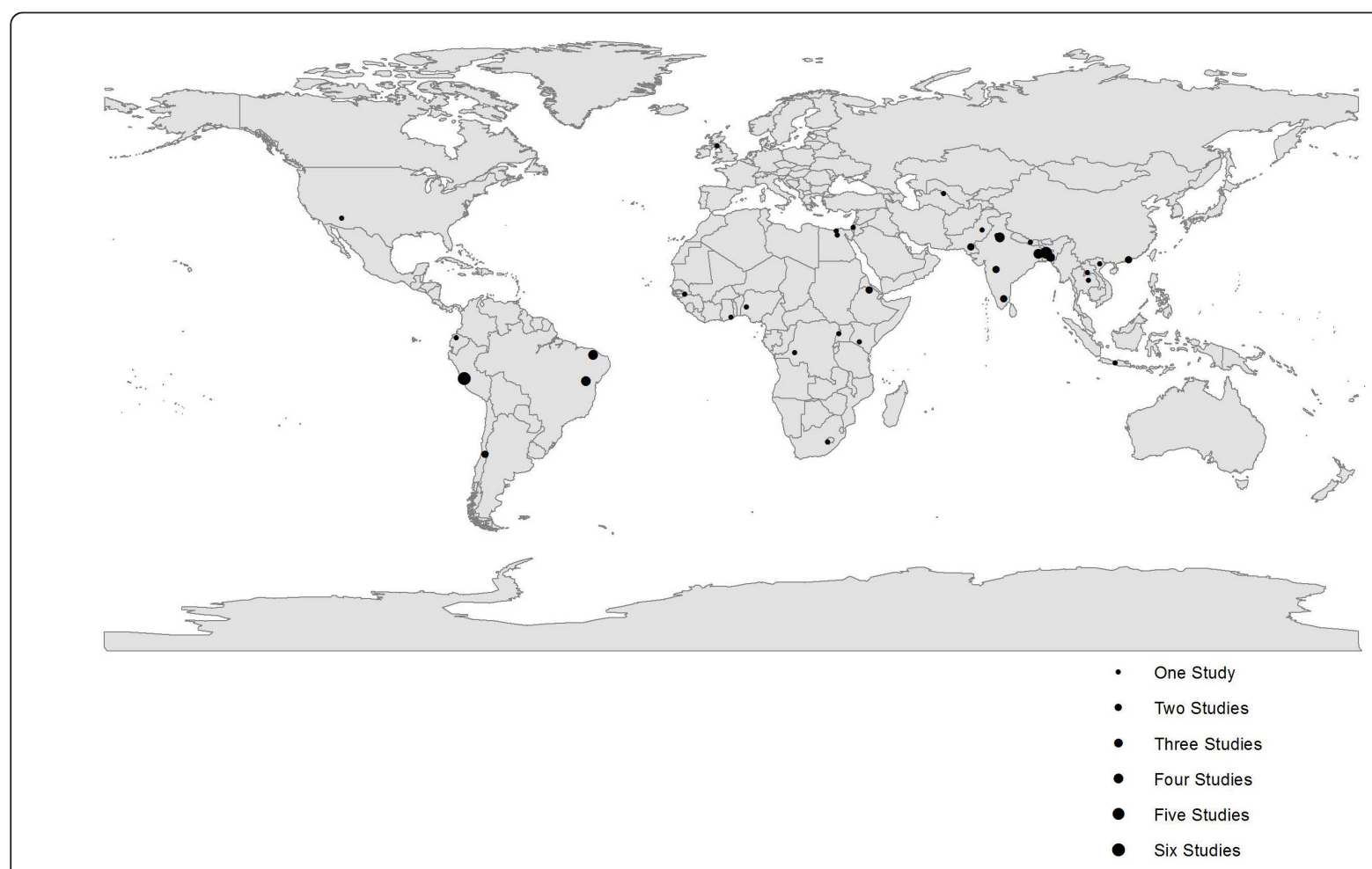

Figure 2 Location of studies reporting diarrhea duration and severity outcomes for children and adults. Locations of 61 unique studies; one study represented at 3 different locations.

Table 2 Estimates of diarrhea duration by age and country income-status

\begin{tabular}{|c|c|c|c|}
\hline Duration Outcome & Study Design & $\begin{array}{c}\text { Study Sites }^{1} \\
\text { N }\end{array}$ & $\begin{array}{c}\text { Combined Estimate } \\
\%(95 \% \mathrm{Cl})\end{array}$ \\
\hline \multicolumn{4}{|l|}{ Low- and middle-income countries } \\
\hline \multicolumn{4}{|c|}{$0-59 \mathrm{mos}$} \\
\hline \multirow[t]{2}{*}{ Weighted Mean ${ }^{2}$} & Community & 29 & $4.3(4.3-4.4)$ \\
\hline & Hospital - Inpatient & 2 & $8.4(8.1-8.8)$ \\
\hline \multirow[t]{2}{*}{ Weighted Median ${ }^{2}$} & Community & 8 & $3.1(3.0-3.2)$ \\
\hline & Hospital - Inpatient & 1 & $2.0(-)$ \\
\hline \multirow[t]{3}{*}{ Weighted Proportion Persistent ${ }^{3}$} & Community & 12 & $4.9(4.6-5.2)$ \\
\hline & Hospital - Inpatient & 4 & $11.1(9.3-12.9)$ \\
\hline & Hospital - Outpatient & 1 & $15.4(-)$ \\
\hline \multicolumn{4}{|c|}{ 5-15 yrs } \\
\hline \multirow[t]{2}{*}{ Mean } & Community & 1 & $2.7(-)$ \\
\hline & $\geq 16 \mathrm{yrs}$ & & \\
\hline \multirow[t]{2}{*}{ Mean } & Community & 1 & $3.0(-)$ \\
\hline & Hospital - Inpatient & 1 & $2.6(-)$ \\
\hline \multicolumn{4}{|l|}{ High-income countries } \\
\hline \multicolumn{4}{|c|}{$0-59 \mathrm{mos}$} \\
\hline Mean & Community & 1 & $2.2(-)$ \\
\hline \multirow[t]{2}{*}{ Median } & Community & 1 & $1.0(-)$ \\
\hline & $\geq 16 \mathrm{yrs}$ & & \\
\hline \multirow[t]{2}{*}{ Mean } & Community & 1 & $2.6(-)$ \\
\hline & Hospital - Outpatient & 1 & $4.6(3.6-5.2)$ \\
\hline
\end{tabular}

'Individual studies may contribute more than one study site $(\mathrm{N})$ to each estimate ${ }^{2}$ Estimates for $\geq 2$ study sites generated by Poisson regression model weighted by sample size ${ }^{3}$ Estimates for $\geq 2$ study sites generated by logistic regression model weighted by sample size 
Table 3 Measures of severity of diarrhea among children 0-59 mos of age by study type

\begin{tabular}{|c|c|c|c|}
\hline & & $\begin{array}{c}\text { Study Sites }^{1} \\
\mathrm{~N}\end{array}$ & $\begin{array}{c}\text { Weighted Mean } 2 \\
\%(95 \% \mathrm{Cl})\end{array}$ \\
\hline \multicolumn{4}{|c|}{ Community } \\
\hline Dehydration & Any & 6 & $7.3(6.6-8.0)$ \\
\hline & Severe & 1 & $10.9(-)$ \\
\hline Vomiting & & 10 & $18.1(17.4-18.7)$ \\
\hline Bloody Stool & & 9 & $8.7(8.2-9.2)$ \\
\hline \multirow[t]{3}{*}{ Stool Frequency ${ }^{3}$} & Frequency $>5$ stools/day & 3 & $13.4(12.5-14.2)$ \\
\hline & Frequency $>3$ stools/day & 2 & $57.5(54.4-60.5)$ \\
\hline & Mean Stool Frequency (stools/day) & 3 & $4.99(4.80-5.18)$ \\
\hline \multicolumn{4}{|c|}{ Hospital Outpatient } \\
\hline \multirow[t]{4}{*}{ Dehydration } & Any & 3 & $51.4(49.1-53.8)$ \\
\hline & Mild & 1 & $32.8(-)$ \\
\hline & Moderate & 4 & $45.1(43.5-46.7)$ \\
\hline & Severe & 2 & $1.4(0.7-2.1)$ \\
\hline Vomiting & & 2 & $55.7(52.8-58.5)$ \\
\hline \multirow[t]{5}{*}{ Stool Frequency $^{3}$} & Low & 1 & $63.4(-)$ \\
\hline & Medium & 1 & $22.7(-)$ \\
\hline & High & 1 & $14.0(-)$ \\
\hline & Frequency $>5$ stools/day & 1 & $55.1(-)$ \\
\hline & Frequency $>3$ stools/day & 3 & $84.4(83.0-85.7)$ \\
\hline \multicolumn{4}{|c|}{ Hospital Inpatient } \\
\hline \multirow[t]{4}{*}{ Dehydration } & Any & 7 & $84.6(83.1-86.1)$ \\
\hline & Mild & 5 & $66.7(63.4-70.0)$ \\
\hline & Moderate & 6 & $18.6(16.2-20.9)$ \\
\hline & Severe & 10 & $8.1(7.6-8.6)$ \\
\hline Vomiting & & 2 & $58.3(54.3-62.2)$ \\
\hline Bloody Stool & & 1 & $16.2(-)$ \\
\hline \multirow[t]{2}{*}{ Stool Frequency $^{3}$} & High & 1 & $53.6(-)$ \\
\hline & Frequency $>5$ stools/day & 1 & $90.0(-)$ \\
\hline Stool Volume & Mean Stool Volume (kg/g/day) & 1 & $52.6(-)$ \\
\hline
\end{tabular}

${ }^{1}$ Individual studies $(n=27)$ may contribute more than one study site $(\mathrm{N})$ to each estimate ${ }^{2}$ Estimates for $\geq 2$ study sites generated by logistic regression model weighted by sample size; mean stool frequency generated by Poisson regression model weighted by sample size ${ }^{3}$ Low defined as $1-5$ stools/day; medium as 6-9 stools/day; and high as $\geq 10$ stools/day

proportion of moderate cases progressing to severe among individuals $\geq 16$ years of age by rounding down the proportion derived for children (1.4\%); thus, of the $5 \%$ of cases characterized as moderate, $1 \%$ (i.e. $0.05 \%$ of all cases) evolve into severe episodes. Approximately 5\% of mild, $30.1 \%$ of moderate and $92.8 \%$ of severe cases result in dehydration. Although we aimed to characterize the duration of mild, moderate, and severe cases using the averages reported by community, hospital inpatient, and hospital outpatient studies, respectively, mean duration was only reported by one included community study (3.0 days) and one included hospital inpatient study (2.6 days). We therefore averaged the duration reported by the two studies and applied this figure (2.8 days) to the duration of mild, moderate, and severe cases.

\section{Discussion}

This systematic review is the first to describe the overall duration and severity of diarrhea among children and adults. To estimate the annual number of diarrhea episodes among children under-five by region, we applied the regional age-adjusted incidences of diarrhea among children 0-59 mos of age to the regional populations of children in that age group. The total number of diarrhea episodes, as well as the breakdown of mild, moderate, and severe episodes in each region, is presented in Table 6. By aggregating the regional numbers, we 
Table 4 Measures of severity of diarrhea among individuals $\geq 16$ yrs of age by country income-status

\begin{tabular}{|c|c|c|c|}
\hline & & $\begin{array}{c}\text { Study Sites } \\
\text { N }\end{array}$ & $\begin{array}{c}\text { Weighted Mean }{ }^{2} \\
\%(95 \% \mathrm{Cl})\end{array}$ \\
\hline \multicolumn{4}{|l|}{ Low- and middle-income countries } \\
\hline \multicolumn{4}{|c|}{ Community } \\
\hline Dehydration & Any & 1 & $5.0(-)$ \\
\hline Vomiting & & 1 & $24.9(-)$ \\
\hline \multicolumn{4}{|c|}{ Hospital Outpatient } \\
\hline Dehydration & Any & 1 & $30.1(-)$ \\
\hline Vomiting & & 1 & $43.3(-)$ \\
\hline Bloody Stool & & 1 & $10.0(-)$ \\
\hline Stool Frequency & Mean Stool Frequency (stools/day) & 1 & $8.1(-)$ \\
\hline \multicolumn{4}{|c|}{ Hospital Inpatient } \\
\hline Dehydration & Any & 2 & $92.8(90.1-95.5)$ \\
\hline & Mild & 1 & $0(-)$ \\
\hline & Moderate & 1 & $72.7(-)$ \\
\hline & Severe & 2 & $40.3(35.2-45.5)$ \\
\hline Vomiting & & 1 & $83.0(-)$ \\
\hline \multicolumn{4}{|l|}{ High-income countries } \\
\hline \multicolumn{4}{|c|}{ Community } \\
\hline Vomiting & & 1 & $75.0(-)$ \\
\hline \multicolumn{4}{|c|}{ Hospital Outpatient } \\
\hline Vomiting & & 1 & $25.9(-)$ \\
\hline
\end{tabular}

${ }^{1}$ Individual studies $(n=4)$ may contribute more than one study site $(\mathrm{N})$ to each estimate ${ }^{2}$ Estimates for $\geq 2$ study sites generated by logistic regression model weighted by sample size

estimate that among the 1.67 billion diarrhea episodes occurring among children under-five globally per year 1.08 billion (64.8\%) are mild; 580 million are moderate (34.7\%); and 8 million (0.5\%) are severe. By region, the

Table 5 Global care-seeking practices for diarrhea episodes among children $\leq \mathbf{3 6}$ mos of age in low- and middle-income countries

\begin{tabular}{cc}
\hline Region & Diarrhea Care-seeking (\%) \\
\hline West/Middle Africa* $^{*}$ & 26.9 \\
\hline South/East Africa** $^{*}$ & 39.1 \\
\hline North Africa/West Asia/Europe $^{\wedge}$ & 41.0 \\
\hline Central Asia $^{\wedge}$ & 35.6 \\
\hline South/Southeast Asia & ${ }^{\dagger}$ \\
\hline Latin America/Caribbean $^{+\dagger}$ & 31.0 \\
\hline Global Median & 34.8 \\
\hline
\end{tabular}

DHS[6] data sources: * Benin 2001, Burkina Faso 1998-99, Cameroon 1998, Chad 1996-97, Cote d'Ivoire 1998-99, Gabon 2000, Ghana 1998, Guinea 1999, Mali 2001, Mauritania 2000-01, Niger 1998, Nigeria 1999, Senegal 1997, Togo 1998. ** Comoros 1996, Eritrea 2002, Ethiopia 2000, Kenya 1998, Madagascar 1997, Malawi 2000, Mozambique 1997, Namibia 2000, Rwanda 2000, South Africa 19998, Tanzania 1999, Uganda 2000-01, Zambia 2001-02, Zimbabwe 1999. ^ Armenia 2000, Egypt 2000, Jordan 2002, Turkey 1998, Yemen 1997. ^ Kazakhstan 1999, Kyrgz Rep. 1997, Turkmenistan 2000, Uzbekistan 1996. ${ }^{\dagger}$ Bangladesh 1999-00, Cambodia 2000, India 1998-99, Indonesia 1997, Nepal 2000, Philippines 1998, Vietnam 1997. ${ }^{+\dagger}$ Bolivia 1998, Brazil 1996, Colombia 2000, Dominican Rep. 2002, Guatemala 1998-99, Haiti 2000, Nicaragua 2001, Peru 2000. burden of diarrhea is greatest in Africa and Asia; still, Table 7 illustrates that episodes occurring in Africa tend to be more serious in duration and severity outcomes.

The total envelope of diarrhea cases among individuals $\geq 16$ years of age is comprised of approximately 430 million annual episodes of diarrhea [2]. We estimate that approximately 408.5 million episodes are mild (95\%); 21.3 million are moderate (4.95\%); and 0.2 million are severe $(0.05 \%)$.

The dearth of studies reporting outcomes for children 5-15 years of age inhibits our ability to directly estimate the burden of diarrhea on this age group. However, a comparison of the mean duration of community-based cases seems to suggest that diarrhea outcomes among children aged 5-15 yrs are more similar to individuals $\geq$ 16 than to children under-five (Table 2). Accordingly, we applied the breakdown of mild, moderate, and severe cases estimated for individuals $\geq 16$ to the total number of incident cases among children 5-15 years of age. We estimate that of the 200 million diarrheal episodes that occur per year among children 5-15 years of age [2], 190 million are mild (95\%); 9.9 million are moderate (4.95\%); and 0.1 million are severe (0.05\%).

Our review is limited in that we cannot extrapolate our findings onto the duration and severity of diarrhea episodes occurring among HIV-infected individuals. 


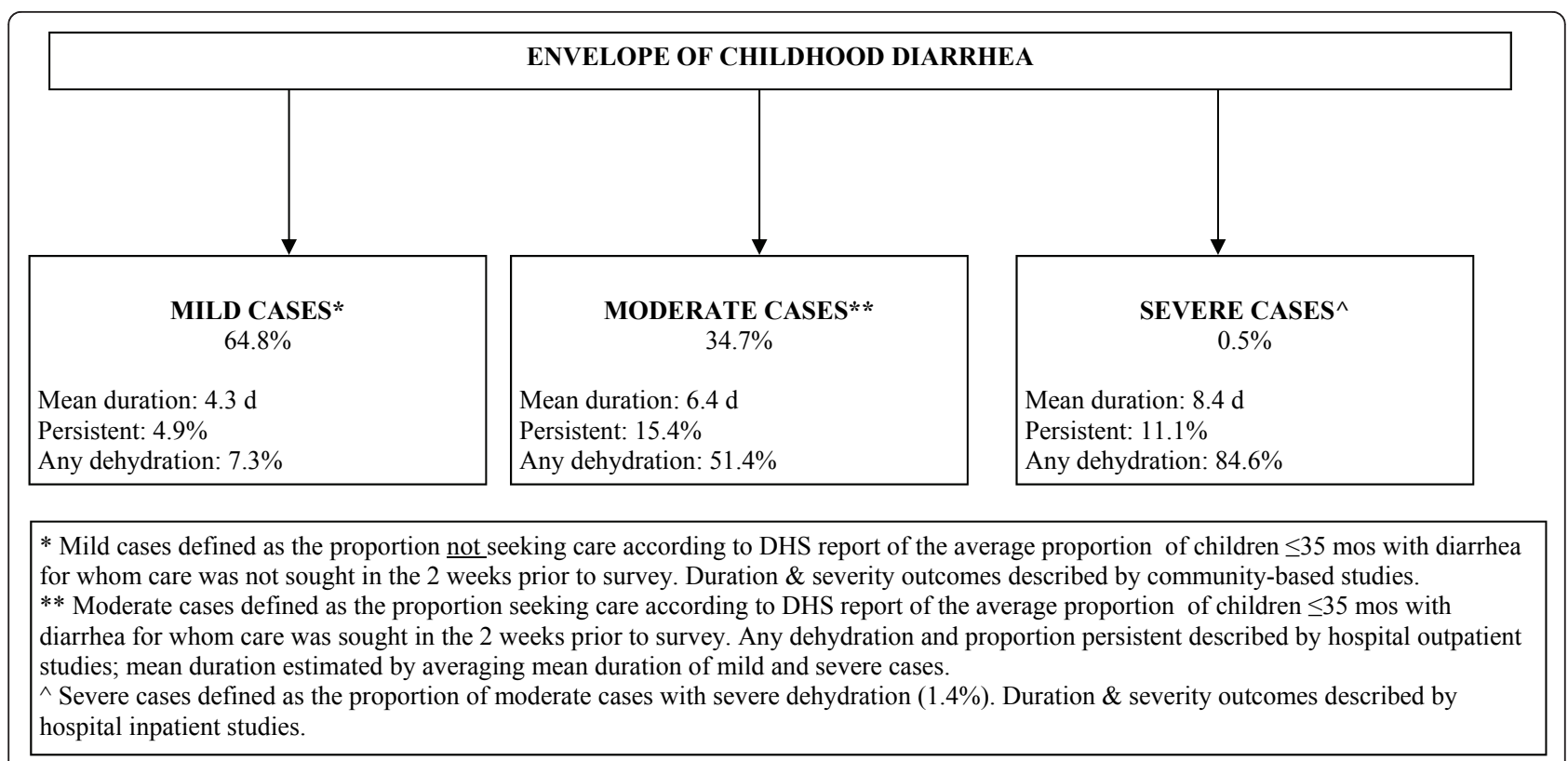

Figure 3 Model of the duration and severity of diarrhea among children 0-59 mos of age.

Research comparing diarrhea morbidity and mortality between individuals of discrepant HIV status has shown that HIV increases susceptibility to infectious diseases, including diarrhea. Of the studies we identified, one excluded study observed that in addition to increased diarrhea incidence, HIV-infected children suffered higher duration and a larger proportion of persistent episodes as compared to uninfected children [69].
Moreover, the same study reported increased diarrhearelated mortality among HIV-infected children.

The proportion of moderate/severe episodes among children under-five, which was estimated using the proportion of episodes for which care was sought, is likely underestimated since appropriate care is sought in less than $30-50 \%$ of cases in resource poor settings [70]. Given that facility care is under-utilized, moderate/

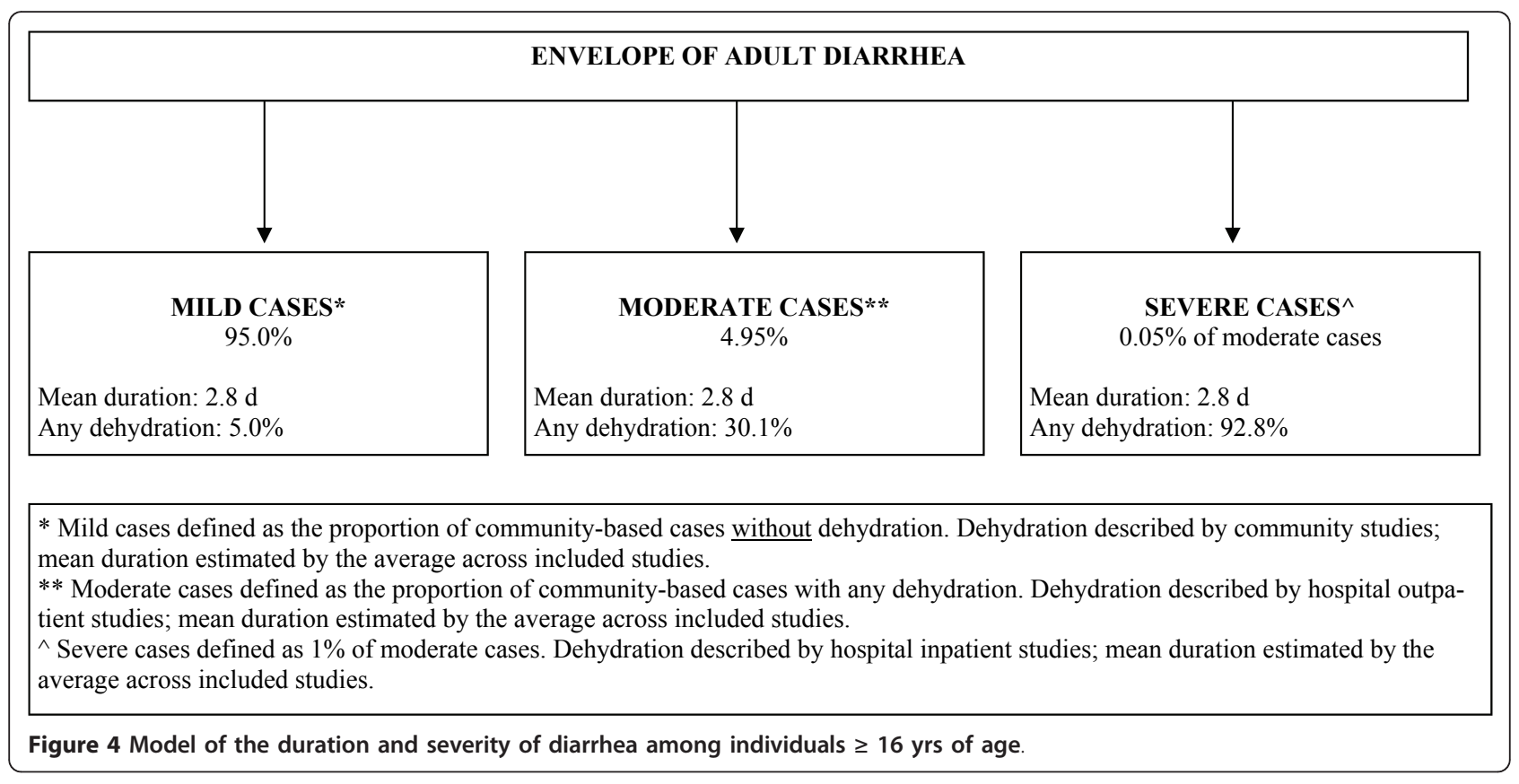


Table 6 Regional breakdown of diarrhea episodes

\begin{tabular}{ccccc}
\hline GBD Region & $\begin{array}{c}\text { Total \# Diarrhea Episodes } \\
\mathbf{0 - 5 9} \text { mos[71]* }\end{array}$ & Total \# Mild Episodes & Total \# Moderate Episodes & Total \# Severe Episodes \\
\hline African & $448,755,780$ & $290,793,745$ & $155,718,256$ & $2,243,779$ \\
\hline Americas & $220,278,200$ & $142,740,274$ & $76,436,535$ & $1,101,391$ \\
\hline Eastern Mediterranean & $199,376,910$ & $129,196,238$ & $69,183,788$ & 996,885 \\
\hline Europe & $111,344,240$ & $72,151,068$ & $38,636,451$ & 556,721 \\
\hline South East Asian & $436,836,240$ & $283,069,884$ & $151,582,175$ & $2,184,181$ \\
\hline Western Pacific & $254,965,120$ & $165,217,398$ & $88,472,897$ & $1,274,826$ \\
\hline Total & $\mathbf{1 , 6 7 1 , 5 5 6 , 4 9 0}$ & $\mathbf{1 , 0 8 3 , 1 6 8 , 6 0 6}$ & $\mathbf{5 8 0 , 0 3 0 , 1 0 2}$ & $\mathbf{8 , 3 5 7 , 7 8 2}$ \\
\hline
\end{tabular}

* Fischer Walker CL, Perin J, Aryee M, C. B-P, Black RE. Diarrhea incidence in low- and middle-income countries in 1990 and 2010. Submitted: BMC Public Health. 2011.

severe episodes among children under-five are also assessed in the community; thus, the duration and severity outcomes derived from community-based studies may not accurately describe mild episodes that do not require facility level care. However, the increasing gravity of duration and severity outcomes across community-based, hospital-inpatient, and hospital-outpatient studies, respectively, suggests that these estimates are plausible and although biased, they represent the best summary of available data.

\section{Conclusions}

In this review we classified the total envelope of diarrheal episodes among individuals 0-59 mos, 5-15 years, and $\geq 16$ years of age according to diarrhea duration and severity. This information is essential to accurately calculate the age-specific burden of disease and the appropriate allocation of DALYs. Given that the global burden of diarrhea consists of large numbers of episodes beyond those progressing to death, the estimated breakdown of mild, moderate, and severe episodes is

Table 7 Comparison of outcomes across Africa and Asia

\begin{tabular}{|c|c|c|c|}
\hline $\begin{array}{l}\text { Study } \\
\text { Period }\end{array}$ & Outcome & Africa & Asia \\
\hline 1987-1991 & Mean Duration $^{1}$ & $4.4(4.3-4.5)^{*}$ & $2.9(2.8-3.0)^{*}$ \\
\hline \multirow[t]{2}{*}{ 1990-1994 } & Mild Dehydration ${ }^{2}$ & $69.8(-)$ & $\underset{* *}{65.6(61.7-69.5)}$ \\
\hline & $\begin{array}{c}\text { Severe } \\
\text { Dehydration }{ }^{2}\end{array}$ & $30.2(-)$ & $7.2(5.4-9.0)^{* *}$ \\
\hline \multirow[t]{2}{*}{ 1992-1998 } & Any Dehydration ${ }^{1}$ & $77.4(-)$ & $1.9(1.4-2.4)^{* *}$ \\
\hline & Vomiting $^{1}$ & $\begin{array}{c}20.3(19.0-21.6) \\
* *\end{array}$ & $19.4 \underset{* *}{(18.0-20.9)}$ \\
\hline \multirow[t]{2}{*}{$2000-2005$} & Mean Duration ${ }^{1}$ & $4.8(4.6-5.1)^{*}$ & $3.4(3.2-3.5)^{*}$ \\
\hline & Median Duration $^{1}$ & $5.0(-)$ & $2.2(2.1-2.3)^{*}$ \\
\hline
\end{tabular}

*Weighted Mean/Median (95\% Cl); community-based studies, only**Weighted $\%(95 \% \mathrm{Cl})$;

${ }^{1}$ Community-based studies, only

${ }^{2}$ Hospital-inpatient studies, only

Data were generated combining estimates for like study designs and outcomes in overlapping study years increasingly important for informing policy decisions on global health. As programs increasingly scale-up and improve diarrhea treatment, especially among children under-five, estimates of diarrhea morbidity should be used to determine the most effective distribution of funds for interventions focused on diarrhea.

\section{Acknowledgements}

We would like to thank Jamie Perin for guidance in the statistical analysis. The study was supported by grants from the Bill and Melinda Gates

Foundation to the US Fund for UNICEF for CHERG and to the University of Washington for the Global Burden of Disease Project. No funding bodies

played any role in the design, writing or decision to publish this manuscript.

\section{Authors' contributions}

LML conducted the systematic review, analysis and led the initial manuscript preparation. CLFW assisted with the analysis and the manuscript preparation. REB provided technical leadership and assisted with the interpretation of the analysis and the final manuscript preparation. All authors read and approved the final manuscript.

\section{Competing interests}

The authors declare that they have no competing interests.

Received: 31 October 2011 Accepted: 6 April 2012

Published: 6 April 2012

\section{References}

1. WHO: Causes of death 2008 summary tables.[http://www.who.int/entity/ gho/mortality_burden_disease/global_burden_disease_DTH6_2008.xls].

2. Fischer-Walker CL, Black RE: Diarrhoea morbidity and mortality in older children, adolescents, and adults. Epidemiol Infect 2010, 138(9):1215-1226.

3. Hjelt K, Grauballe PC, Andersen L, Schiotz PO, Howitz P, Krasilnikoff PA: Antibody response in serum and intestine in children up to six months after a naturally acquired rotavirus gastroenteritis. J Pediatr Gastroenterol Nutr 1986, 5(1):74-80.

4. Ruuska T, Vesikari T: Rotavirus disease in Finnish children: use of numerical scores for clinical severity of diarrhoeal episodes. Scand J Infect Dis 1990, 22(3):259-267.

5. Clark HF, Borian FE, Bell LM, Modesto K, Gouvea V, Plotkin SA: Protective effect of WC3 vaccine against rotavirus diarrhea in infants during a predominantly serotype 1 rotavirus season. I Infect Dis 1988, 158(3):570-587.

6. MEASURE DHS: DHS Comparative Reports: Child Morbidity and Treatment Patterns.Edited by: ORC Macro. Calverton, Maryland, USA; 2004:.

7. Stata Corp: Statistical Software: Release 10.1. College Station, TX: Stata Corporation; 2008.

8. Ahmed FU, Karim E: Children at risk of developing dehydration from diarrhoea: a case-control study. J Trop Pediatr 2002, 48(5):259-263. 
9. Bahl R, Bhandari N, Saksena M, Strand T, Kumar GT, Bhan MK, Sommerfelt H: Efficacy of zinc-fortified oral rehydration solution in 6- to 35-month-old children with acute diarrhea. J Pediatr 2002, 141(5):677-682.

10. Baqui AH, Black RE: El Arifeen S, Yunus M, Chakraborty J, Ahmed S, Vaughan JP: Effect of zinc supplementation started during diarrhoea on morbidity and mortality in Bangladeshi children: community randomised trial. BMJ 2002, 325(7372):1059.

11. Bhandari N, Bhan MK, Sazawal S: Mortality associated with acute watery diarrhea, dysentery and persistent diarrhea in rural north India. Acta Paediatr Suppl 1992, 381:3-6.

12. Biswas R, Biswas AB, Manna B, Bhattacharya SK, Dey R, Sarkar S: Effect of vitamin $A$ supplementation on diarrhoea and acute respiratory tract infection in children. A double blind placebo controlled trial in a Calcutta slum community. Eur J Epidemiol 1994, 10(1):57-61.

13. Brunser O, Espinoza J, Araya M, Pacheco I, Cruchet S: Chronic iron intake and diarrhoeal disease in infants. A field study in a less-developed country. Eur J Clin Nutr 1993, 47(5):317-326.

14. Castro MX, Soares AM, Fonseca W, Rey LC, Guerrant RL, Lima AA: Common infectious diseases and skin test anergy in children from an urban slum in northeast Brazil. Braz J Infect Dis 2003, 7(6):387-394.

15. Checkley W, Gilman RH, Black RE, Lescano AG, Cabrera L, Taylor DN, Moulton LH: Effects of nutritional status on diarrhea in Peruvian children. J Pediatr 2002, 140(2):210-218.

16. Chow CM, Choi K, Nelson EA, Chan PK, Mast TC, DiStefano D, Tam JS, Bresee JS: Use of intravenous fluids in Hong Kong children hospitalised for diarrhoea and relationship to severity and aetiology. Vaccine 2009, 27(Suppl 5):F55-F60

17. Melo MC, Taddei JA, Diniz-Santos DR, Vieira C, Carneiro NB, Melo RF, Silva LR: Incidence of diarrhea in children living in urban slums in Salvador, Brazil. Braz J Infect Dis 2008, 12(1):89-93.

18. Dibley MJ, Sadjimin T, Kjolhede CL, Moulton LH: Vitamin A supplementation fails to reduce incidence of acute respiratory illness and diarrhea in preschool-age Indonesian children. J Nutr 1996, 126(2):434-442.

19. Dutta P, Lahiri M, Sen D, Pal SC: Prospective hospital based study on persistent diarrhoea. Gut 1991, 32(7):787-790.

20. Ferreccio C, Prado V, Ojeda A, Cayyazo M, Abrego P, Guers L, Levine MM: Epidemiologic patterns of acute diarrhea and endemic Shigella infections in children in a poor periurban setting in Santiago, Chile. Am J Epidemiol 1991, 134(6):614-627.

21. Fischer Walker CL, Bhutta ZA, Bhandari N, Teka T, Shahid F, Taneja S, Black RE: Zinc supplementation for the treatment of diarrhea in infants in Pakistan, India and Ethiopia. J Pediatr Gastroenterol Nutr 2006, 43(3):357-363.

22. Gupta DN, Sircar BK, Sengupta PG, Ghosh S, Banu MK, Mondal SK, Saha DR, De SP, Sikdar SN, Manna B, et al: Epidemiological and clinical profiles of acute invasive diarrhoea with special reference to mucoid episodes: a rural community-based longitudinal study. Trans $R$ Soc Trop Med Hyg 1996, 90(5):544-547.

23. Haque R, Mondal D, Kirkpatrick BD, Akther S, Farr BM, Sack RB, Petri WA Jr: Epidemiologic and clinical characteristics of acute diarrhea with emphasis on Entamoeba histolytica infections in preschool children in an urban slum of Dhaka, Bangladesh. Am J Trop Med Hyg 2003, 69(4):398-405.

24. Herbst S, Fayzieva D, Kistemann T: Risk factor analysis of diarrhoeal diseases in the Aral Sea area (Khorezm, Uzbekistan). Int J Environ Health Res 2008, 18(5):305-321.

25. Kolstad PR, Burnham G, Kalter HD, Kenya-Mugisha N, Black RE: The integrated management of childhood illness in western Uganda. Bull World Health Organ 1997, 75(Suppl 1):77-85.

26. Lanata CF, Black RE, Gilman RH, Lazo F, Del Aguila R: Epidemiologic, clinical, and laboratory characteristics of acute vs. persistent diarrhea in periurban Lima, Peru. J Pediatr Gastroenterol Nutr 1991, 12(1):82-88,

27. Lanata CF, Black RE, Maurtua D, Gil A, Gabilondo A, Yi A, Miranda E, Gilman RH, Leon-Barua R, Sack RB: Etiologic agents in acute vs persistent diarrhea in children under three years of age in peri-urban Lima, Peru. Acta Paediatr Suppl 1992, 381:32-38.

28. Lima AA, Moore SR, Barboza MS Jr, Soares AM, Schleupner MA, Newman RD, Sears CL, Nataro JP, Fedorko DP, Wuhib T, et al: Persistent diarrhea signals a critical period of increased diarrhea burdens and nutritional shortfalls: a prospective cohort study among children in northeastern Brazil. J Infect Dis 2000, 181(5):1643-1651.

29. Manun'ebo MN, Haggerty PA, Kalengaie M, Ashworth A, Kirkwood BR: Influence of demographic, socioeconomic and environmental variables on childhood diarrhoea in a rural area of Zaire. J Trop Med Hyg 1994, 97(1):31-38.

30. Mirza NM, Caulfield LE, Black RE, Macharia WM: Risk factors for diarrheal duration. Am J Epidemiol 1997, 146(9):776-785.

31. Mitra AK, Akramuzzaman SM, Fuchs GJ, Rahman MM, Mahalanabis D: Longterm oral supplementation with iron is not harmful for young children in a poor community of Bangladesh. J Nutr 1997, 127(8):1451-1455.

32. Moore SR, Lima AA, Schorling JB, Barboza MS Jr: Soares AM, Guerrant RL: Changes over time in the epidemiology of diarrhea and malnutrition among children in an urban Brazilian shantytown, 1989 to 1996. Int Infect Dis 2000, 4(4):179-186.

33. Newman RD, Sears CL, Moore SR, Nataro JP, Wuhib T, Agnew DA Guerrant RL, Lima AA: Longitudinal study of Cryptosporidium infection in children in northeastern Brazil. J Infect Dis 1999, 180(1):167-175.

34. Oberhelman RA, Gilman RH, Sheen P, Taylor DN, Black RE, Cabrera L, Lescano AG, Meza R, Madico G: A placebo-controlled trial of Lactobacillus GG to prevent diarrhea in undernourished Peruvian children. J Pediatr 1999, 134(1):15-20.

35. Oni GA, Schumann DA, Oke EA: Diarrhoeal disease morbidity, risk factors and treatments in a low socioeconomic area of Ilorin, Kwara State, Nigeria. J Diarrhoeal Dis Res 1991, 9(3):250-257.

36. Pathela P, Zahid Hasan K, Roy E, Huq F, Kasem Siddique A, Bradley Sack R: Diarrheal illness in a cohort of children 0-2 years of age in rural Bangladesh: I. Incidence and risk factors. Acta Paediatr 2006, 95(4):430-437.

37. Rahmathullah L, Underwood BA, Thulasiraj RD, Milton RC: Diarrhea, respiratory infections, and growth are not affected by a weekly lowdose vitamin A supplement: a masked, controlled field trial in children in southern India. Am J Clin Nutr 1991, 54(3):568-577.

38. Ramakrishnan U, Latham MC, Abel R, Frongillo EA Jr: Vitamin A supplementation and morbidity among preschool children in south India. Am J Clin Nutr 1995, 61(6):1295-1303.

39. Sachdev HP, Kumar S, Singh KK, Satyanarayana L, Puri RK: Risk factors for fatal diarrhea in hospitalized children in India. J Pediatr Gastroenterol Nutr 1991, 12(1):76-81.

40. Sempertegui F, Estrella B, Egas J, Carrion P, Yerovi L, Diaz S, Lascano M, Aranha R, Ortiz W, Zabala A, et al: Risk of diarrheal disease in Ecuadorian day-care centers. Pediatr Infect Dis J 1995, 14(7):606-612.

41. Strina A, Cairncross S, Prado MS, Teles CA, Barreto ML: Childhood diarrhoea symptoms, management and duration: observations from a longitudinal community study. Trans R Soc Trop Med Hyg 2005, 99(6):407-416.

42. Sutra S, Srisontrisuk S, Panpurk W, Sutra P, Chirawatkul A, Snongchart N, Kusowon P: The pattern of diarrhea in children in Khon Kaen, northeastern Thailand: I. The incidence and seasonal variation of diarrhea. Southeast Asian J Trop Med Public Health 1990, 21(4):586-593.

43. Teka T, Faruque AS, Fuchs GJ: Risk factors for deaths in under-age-five children attending a diarrhoea treatment centre. Acta Paediatr 1996, 85(9):1070-1075

44. Tielsch JM, Khatry SK, Stoltzfus RJ, Katz J, LeClerq SC, Adhikari R, Mullany LC Shresta S, Black RE: Effect of routine prophylactic supplementation with iron and folic acid on preschool child mortality in southern Nepal: community-based, cluster-randomised, placebo-controlled trial. Lancet 2006, 367(9505):144-152

45. Valois S, Costa-Ribeiro H Jr: Mattos A, Ribeiro TC, Mendes CM, Lifshitz F: Controlled, double-blind, randomized clinical trial to evaluate the impact of fruit juice consumption on the evolution of infants with acute diarrhea. Nutr J 2005, 4:23.

46. van der Hoek W, Feenstra SG, Konradsen F: Availability of irrigation water for domestic use in Pakistan: its impact on prevalence of diarrhoea and nutritional status of children. J Health Popul Nutr 2002, 20(1):77-84

47. Yassin K: Morbidity and risk factors of diarrheal diseases among underfive children in rural Upper Egypt. J Trop Pediatr 2000, 46(5):282-287.

48. Santosham M, Sack RB, Reid R, Black R, Croll J, Yolken R, Aurelian L, Wolff M, Chan E, Garrett $S$, et al: Diarrhoeal diseases in the White Mountain Apaches: epidemiologic studies. J Diarrhoeal Dis Res 1995, 13(1):18-28.

49. Abu-Elyazeed RR, Wierzba TF, Frenck RW, Putnam SD, Rao MR, Savarino SJ, Kamal KA, Peruski LF Jr, Abd-El Messih IA, El-Alkamy SA, et al: Epidemiology 
of Shigella-associated diarrhea in rural Egyptian children. Am J Trop Med Hyg 2004, 71(3):367-372.

50. Bahl R, Bhandari N, Hambidge KM, Bhan MK: Plasma zinc as a predictor of diarrheal and respiratory morbidity in children in an urban slum setting. Am J Clin Nutr 1998, 68(2 Suppl):414S-417S

51. Baqui AH, Zaman K, Persson LA: El Arifeen S, Yunus M, Begum N, Black RE: Simultaneous weekly supplementation of iron and zinc is associated with lower morbidity due to diarrhea and acute lower respiratory infection in Bangladeshi infants. J Nutr 2003, 133(12):4150-4157.

52. Barreto ML, Milroy CA, Strina A, Prado MS, Leite JP, Ramos EA, Ribeiro H, Alcantara-Neves NM, Teixeira Mda G, Rodrigues LC, et al: Communitybased monitoring of diarrhea in urban Brazilian children: incidence and associated pathogens. Trans R Soc Trop Med Hyg 2006, 100(3):234-242.

53. Basak S, Chakraborty PS, Chandy J, Bhattacharya MK, Rasaily R, Ramamurthy T, Sen M: Aetiological studies on hospital inpatients with secretory diarrhoea in Calcutta. J Indian Med Assoc 1992, 90(1):14-15, 16.

54. Daniels DL, Cousens SN, Makoae LN, Feachem RG: A case-control study of the impact of improved sanitation on diarrhoea morbidity in Lesotho. Bull World Health Organ 1990, 68(4):455-463.

55. Hori H, Akpedonu P, Armah G, Aryeetey M, Yartey J, Kamiya H, Sakurai M: Enteric pathogens in severe forms of acute gastroenteritis in Ghanaian children. Acta Paediatr Jpn 1996, 38(6):672-676.

56. Lulseged S: Predictors of moderate to severe dehydration in acute diarrhoeal disease: a case-control study. Ethiop Med J 1992, 30(2):69-78.

57. Nguyen TV, Le Van P, Le Huy C, Weintraub A: Diarrhea caused by rotavirus in children less than 5 years of age in Hanoi, Vietnam. J Clin Microbiol 2004, 42(12):5745-5750.

58. Patel A, Dibley MJ, Mamtani M, Badhoniya N, Kulkarni H: Zinc and copper supplementation in acute diarrhea in children: a double-blind randomized controlled trial. BMC Med 2009, 7:22.

59. Penny ME, Peerson JM, Marin RM, Duran A, Lanata CF, Lonnerdal B, Black RE, Brown KH: Randomized, community-based trial of the effect of zinc supplementation, with and without other micronutrients, on the duration of persistent childhood diarrhea in Lima, Peru. J Pediatr 1999, 135(2 Pt 1):208-217.

60. Qazi R, Sultana S, Sundar S, Warraich H: un-Nisa T, Rais A, Zaidi AK: Population-based surveillance for severe rotavirus gastroenteritis in children in Karachi, Pakistan. Vaccine 2009, 27(Suppl 5):F25-F30.

61. Sodemann M, Jakobsen MS, Molbak K, Martins C, Aaby P: Maternal perception of cause, signs and severity of diarrhoea in a suburban west African community. Acta Paediatr 1996, 85(9):1062-1069.

62. Aloun DS, Nyambat B, Phetsouvanh R, Douangboupha V, Keonakhone P, Xoumphonhphakdy B, Vongsouvath M, Kirkwood C, Bogdanovic-Sakran N, Kilgore PE: Rotavirus diarrhoea among children aged less than 5 years at Mahosot Hospital, Vientiane, Lao PDR. Vaccine 2009, 27(Suppl 5):F85-F88.

63. Zodpey SP, Deshpande SG, Ughade SN, Hinge AV, Shirikhande SN: Risk factors for development of dehydration in children aged under five who have acute watery diarrhoea: a case-control study. Public Health 1998, 112(4):233-236.

64. Chan SS, Ng KC, Lam PK, Lyon DJ, Cheung WL, Rainer TH: Predictors of positive stool culture in adult patients with acute infectious diarrhea. $J$ Emerg Med 2002, 23(2):125-130.

65. Dryden MS, Gabb RJ, Wright SK: Empirical treatment of severe acute community-acquired gastroenteritis with ciprofloxacin. Clin Infect Dis 1996, 22(6):1019-1025.

66. Pereg D, Kimhi O, Tirosh A, Orr N, Kayouf R, Lishner M: The effect of fermented yogurt on the prevention of diarrhea in a healthy adult population. Am J Infect Control 2005, 33(2):122-125.

67. Seas C, Alarcon M, Aragon JC, Beneit S, Quinonez M, Guerra H, Gotuzzo E: Surveillance of bacterial pathogens associated with acute diarrhea in Lima, Peru. Int J Infect Dis 2000, 4(2):96-99.

68. Weil AA, Khan Al, Chowdhury F, Larocque RC, Faruque AS, Ryan ET, Calderwood SB, Qadri F, Harris JB: Clinical outcomes in household contacts of patients with cholera in Bangladesh. Clin Infect Dis 2009, 49(10):1473-1479.

69. Nte AR, Eneh AU: HIV infection and persistent diarrhoea: a comparative study of HIV positive and HIV negative children. Afr J Med Med Sci 2008, 37(2):149-155.

70. Boschi-Pinto C, Lanata C, RE B: The global burden of childhood diarrhoea. In Maternal and Child Health: Global Challenges, Problems, and Policies. Edited by: JE. Washington, D.C.: Springer Publishers; 2009:, edn.
71. Fischer Walker CL, Perin J, Aryee M, CB-P , Black RE: Diarrhea incidence in low- and middle-income countries in 1990 and 2010: a systematic review. BMC Public Health 2012, 12-220.

\section{Pre-publication history}

The pre-publication history for this paper can be accessed here: http://www.biomedcentral.com/1471-2458/12/276/prepub

\section{doi:10.1186/1471-2458-12-276}

Cite this article as: Lamberti et al: Systematic review of diarrhea duration and severity in children and adults in low- and middle-income countries. BMC Public Health 2012 12:276.

\section{Submit your next manuscript to BioMed Central and take full advantage of:}

- Convenient online submission

- Thorough peer review

- No space constraints or color figure charges

- Immediate publication on acceptance

- Inclusion in PubMed, CAS, Scopus and Google Scholar

- Research which is freely available for redistribution 